\title{
Interdisciplinaridade e transversalidade: considerações sobre a epistemologia do trabalho escolar brasileiro
}

\author{
Alexandre Costa
}

\begin{abstract}
The aim of this paper is to rethink the concepts of 'transversality'(the transversal themes' approach) and 'interdisciplinarity' as they were constructed in the Brazilian National Syllabus and instantiated in two Applied Linguistics studies. From their emergency in an analysis of English teachers' practical theories, these notions are considered in another study about school practices and reviewed in their epistemological and discursive characteristics.
\end{abstract}

Key words: School practices, transversality, interdisciplinarity.

O objetivo deste artigo é discutir a matriz epistemológica do trabalho escolar no ensino brasileiro tal como foi constituída nos Parâmetros Curriculares Nacionais ${ }^{1}$ (Brasil, 1998). Partindo da consideração de uma análise de "teorias práticas" de professores de língua inglesa (Pessoa, 2002; 2005) e de uma proposta de operacionalização da perspectiva dos PCN nas práticas escolares (Kleiman e Moraes, 1999), revisamos um aparente problema teórico da primeira concepção da relação entre as noções de interdisciplinaridade e de transversalidade nas diretrizes oficiais e sua reprodução nas reformulações posteriores.

Na primeira parte da reflexão, tais questões serão inferidas de um estudo pertencente à vertente de Lingüística Aplicada (LA) de língua estrangeira ${ }^{2}$, no qual, apesar de mostrar-se a influência dos PCN nas concepções teóricas dos professores entrevistados, reiteram-se em seus dados as dúvidas de seus sujeitos de pesquisa acerca da abordagem transversal no ensino de língua in-

1. De agora em diante referidos como 'PCN'.

2. A interlocução entre a minha pesquisa de doutoramento em Lingüística Aplicada (Costa, 2007), na Universidade Estadual de Campinas (Unicamp), e as pesquisas desenvolvidas em minha instituição de origem constitui a origem desta reflexão. A questão da emergência da transversalidade em reflexões críticas de professores de inglês foi-me apresentada pela Profa. Dra. Rosane Rocha Pessoa, minha colega, que, muito gentilmente, permitiu-me ter acesso à sua pesquisa, ainda antes de sua publicação e, desde então, tem sido uma parceira especial na reflexão sobre o tema. 
glesa. Na segunda, analisaremos a instanciação dos conceitos de transversalidade e de interdisciplinaridade em outra abordagem da LA, da área de língua materna, localizando em sua perspectiva de operacionalização das práticas escolares a explicitação dos referidos problemas teóricos. Na terceira, finalmente, revisaremos a dimensão epistemológica das abordagens transversal e interdisciplinar no trabalho escolar, situando-as no âmbito da reflexão prática dos professores.

\section{A emergência da noção de transVersalidade em UM ESTUdo SObre 'teO- RIAS PRÁTICAS' DE PROFESSORES DE LÍNGUA ESTRANGEIRA}

Em retomada de sua pesquisa de doutoramento, Pessoa (2005: 1) propõe-se a reexaminar "as reflexões de quatro professores de Inglês sobre sua prática pedagógica e sobre as consequiências dessa prática para os alunos". Por meio de entrevistas semi-estruturadas de caráter reflexivo ${ }^{3}$, a autora produzira dados em contexto interativo com vistas a reconstruir, naquele âmbito de pesquisa, os paradigmas e questionamentos dos professores. Seu foco eram as chamadas "teorias práticas", revisitadas no trabalho seguinte, à luz do processo de formação de professores. Também designadas como "teorias pessoais" ou "teorias implícitas", as teorias práticas são definidas pela autora, mediante uma detalhada revisão bibliográfica ${ }^{4}$, como "sínteses dinâmicas de conhecimentos e crenças a que os professores recorrem ao interpretar o currículo e colocá-lo em prática" (idem, ibidem: 2). Tratase do conhecimento constituído pelo professor acerca de elementos relativos às práticas de ensino como 'objetivos', 'conteúdos' e 'estratégias', entre outros, que parametrizam o trabalho docente.

Nosso interesse por essa mobilização da reflexão dos professores diz respeito à emergência da noção de transversalidade, sempre como ponto de tensão. Nesse sentido, é relevante reproduzir o início do processo de entrevistas, no qual já se revelam dúvidas e problemas apontados pelos professores

3. Segundo a autora, as entrevistas reflexivas buscam fortalecer os sujeitos de campo por meio de sua discussão sobre a própria prática e não apenas gerar dados para o pesquisador.

4. Entre outros: Marrero (1991), García (1999), Britzman (1991), Zeichner e Liston (1996), Pennycook (1989), Edge e Richards (1998), Johnson e Freeman (2001), Alarcão (1996), Van Lier (1994), Van Manem (1991), Nóvoa (1997), Mezirow (1990), Solomon (1987), Ur (1996), Oprandy, Golden e Shiomi (1999) Zeichner 2001), Yonemura (1982), Waite (1993), Magalhães (2002) e Telles (1996). A reprodução dessa parte da pesquisa escapa aos nossos objetivos e, por isso, remetemos o leitor ao trabalho da autora. 
em relação à escolha entre as práticas centradas na leitura e as dirigidas por exercícios comunicativos. Essa dicotomia conformará o contexto de aparecimento do problema da abordagem transversal nas reflexões dos entrevistados (idem, ibidem: 6):

Os dois temas - conteúdo e objetivos do ensino de inglês na escola pública - surgiram na primeira sessão de reflexão da aula de Ana Clara. Sua aula objetivou trabalhar as habilidades orais e dividiu-se em quatro estágios: aquecimento (warmer), apresentação, prática e produção. Márcia foi quem introduziu o tópico central de reflexão com a pergunta: "Qual seria o objetivo de ensinar inglês para a $5^{a}$ série?". Basicamente, duas teorias práticas foram mobilizadas. De um lado, estão Márcia, Jonas e Pedro Henrique, que defendem o foco na leitura, já que a necessidade dos alunos brasileiros é ler e não falar, embora não descartem o trabalho com as habilidades orais, e, de outro, Ana Clara, que faz a defesa do foco nas habilidades orais: "acho mais do que justo você ter uma aula de língua estrangeira, na qual você possa praticar as quatro habilidades. (...) O professor tem a obrigação de dar essa oportunidade aos alunos, porque eles gostam e querem falar inglês".

O debate entre os sujeitos de pesquisa é, na verdade, uma polêmica fundada pelos PCN dirigidos ao ensino de língua estrangeira. O documento oficial (1998: 19-21) argumenta em favor da inclusão do ensino de língua estrangeira nas escolas públicas como parte das atividades de letramento ${ }^{5}$ e de formação geral dos alunos. A assim chamada "justificativa social" para a inclusão do ensino de línguas estrangeiras no currículo do Ensino Fundamental e Médio parte do princípio de que as demandas de leitura, sobretudo, são as possíveis e desejáveis para a educação pública. Seja como decorrência da constatação do fracasso sistemático da escola pública na formação para a proficiência em línguas estrangeiras, seja como conseqüência da tentativa de associar a área à proposta geral dos PCN de formação para a cidadania, o documento preconiza a leitura como atividade central das práticas de ensino de língua estrangeira. Na sessão de entrevista citada acima, os professores reproduzem a discussão instaurada pelo documento, o que é previsível em reflexões práticas de profissionais formados em uma perspectiva diferente: em sua graduação esses professores estavam orientados para a proficiência e não para a instrumentalização em uma habilidade apenas (o privilégio da leitura).

5. Letramento tem sido definido como "um conjunto de práticas sociais que usam a escrita, enquanto sistema simbólico e enquanto tecnologia, em contextos específicos, para objetivos específicos" (Scribner e Cole, 1981 apud Kleiman, 1995: 19). 
Já nas sessões de entrevista seguintes, esse centro de atenção primário será vinculado aos temas transversais (idem, ibidem: 7 e 8):

Na segunda sessão de reflexão, uma discussão sobre temas é desencadeada, pelo fato de Pedro Henrique não ter trabalhado um tema do projeto da escola em sua aula. Sua explicação é que temas como "violência" são difíceis de ser trabalhados. Duas teorias práticas são desveladas nesta sessão. Como resultado de diferentes experiências de formação, Márcia e Jonas acreditam que os temas devem ser o elemento central de suas aulas e que a maneira mais natural de trabalhá-los é por meio da leitura. Para Márcia, o ensino de inglês "tem que partir de algum tema, porque se não a aula fica vazia" e, para Jonas, o trabalho com temas é até mesmo uma forma de compensar os resultados nem sempre positivos no que se refere à aprendizagem da língua. Ele afirma que alguns aprendem, "mas infelizmente a maioria parece que não consegue sair falando 'Oh, my name is fulana, I'm from Brazil.."'. E argumenta que trabalhando "Família", por exemplo, "pelo menos alguma coisa fica, às vezes melhora o relacionamento do filho em casa com o pai".

[...] Na terceira sessão de reflexão, sobre a aula de Jonas, o tópico "temas" volta a ser discutido, porque Ana Clara afirma que "tanto faz utilizar um livro ou trabalhar com temas, que a frustração em termos de língua é sempre a mesma". Para Jonas, o aluno "não vai aprender tudo, mas alguma coisa ele tem que aprender: ele tem que saber falar sobre ele, tem que saber falar sobre a família dele, sobre as coisas que ele gosta, sobre o país, sobre a cidade, em inglês. [...]. [Mas], pelas condições de trabalho, pela quantidade de alunos e o número de aulas, o aluno não vai aprender a falar e a ouvir, não vai sair falando inglês. Se você estiver pensando assim, você vai ficar frustrada". Aqui, despontam dois pontos de vista diversos, de Jonas e Márcia, que trabalham com temas. Enquanto Jonas defende o desenvolvimento da habilidade oral, ainda que o objetivo não seja a proficiência, Márcia enfatiza a aquisição da língua por meio da leitura, embora não descarte totalmente o desenvolvimento das habilidades orais.

Nesses trechos, as questões levantadas pelos professores distribuemse em duas perspectivas diferentes. Uma delas é centrada em dificuldades, seja a de acompanhar uma determinada abordagem sobre os temas transversais, executada na escola por meio de projetos, seja a de lidar com o fracasso no desenvolvimento de habilidades comunicativas em língua inglesa, no contexto da escola pública. A outra diz respeito à organização das aulas em torno dos temas e à prioridade de sua vinculação às atividades de leitura. Em grande medida, os professores ainda estão reproduzindo os pontos fun- 
damentais da proposta dos PCN para o ensino de LE, bem como parte de sua justificativa. No entanto, apesar da referência a tópicos como "violência", "família", "país" e "cidade", como remissão aos temas transversais, o debate parece estabilizar-se novamente ao redor da centralidade da leitura nas práticas de sala de aula, em oposição ao uso tradicional da abordagem comunicativa $^{6}$. Em outras palavras, o exame dos processos de referenciação, de progressão textual e de estrutura argumentativa que se inferem das reflexões dos professores sempre aponta para a polêmica já referida da centralidade da leitura nas aulas de Inglês.

Assim, este estudo específico sobre a reflexão prática de professores de língua estrangeira é relevante para a discussão epistemológica da transversalidade porque não apenas permite localizar a influência do discurso pedagógico dos PCN nas reflexões dos professores, mas também por deixar claro em que aspecto isso ocorre: na apropriação polêmica da prioridade do trabalho com leitura. Seus dados mostram que as referências à transversalidade não apenas estão a serviço da reflexão sobre o letramento, mas a ela reduzidas. Além disso, um segundo aspecto importante, como os dados reproduzidos a seguir deixam ver, é o fato de os professores reiterarem, sistematicamente, a "necessidade" e a "impossibilidade" da produção de práticas de ensino centradas em "temas", sobretudo nos momentos em que Pessoa identifica o que ela chama de formação de "consensos" (idem, ibidem: 8 e 9 - grifos nossos):

A oitava sessão tem como objeto de reflexão a aula de Márcia, na qual um texto em inglês sobre o Parque das Emas foi trabalhado: primeiramente, o tema foi discutido em português, depois eles buscaram as cognatas e, em seguida, a professora escreveu no quadro as idéias do texto em português. Jonas é quem levanta uma questão novamente voltada ao conteúdo: "os objetivos de língua inglesa, havia algum?" Pedro Henrique acha que Márcia deveria ter apresentado e praticado o vocabulário em inglês antes de dar o texto. A teoria que se constrói aqui é que é possível "trabalhar temas dentro da língua inglesa", de Pedro Henrique e Jonas. Essa aula leva Ana Clara a reafirmar sua teoria de que "no caso do ensino de inglês no nível fundamental, vale a pena trabalhar outras habilidades também", mas ela começa a rever sua concepção, na medida em que reconhece a importância do trabalho com temas, porque

6. A chamada 'abordagem comunicativa', fartamente conhecida entre os professores e estudiosos do ensino de LE, constitui-se a partir da apresentação de contextos de comunicação retirados das práticas sociais e adaptados às práticas de ensino. Via de regra, portanto, não se trata de um "uso real da linguagem", mas de sua conversão a atividades pedagógicas que visam a desenvolver as chamadas "quatro habilidades": fala, escuta, leitura e escrita de enunciados. 
os alunos têm pouco conhecimento geral. Nesse momento, uma outra teoria é construída por Pedro Henrique e Jonas: a ênfase na leitura e na escrita vale, sobretudo para as $7^{\text {as }}$ e $8^{\text {as }}$ séries, porque, nas $5^{\text {as }}$ e $6^{\text {as }}$ séries, a ênfase deve ser dada às habilidades orais, visto que os alunos querem falar. Para eles, essa é uma forma de primeiro os alunos se familiarizarem com estruturas básicas da língua, que lhes auxiliarão nas atividades de leitura. No entanto, ela é rejeitada por Márcia, o que se pode perceber na seguinte afirmação: "Você não precisa da gramática para você ler o texto". Entretanto, uma teoria consensual dos quatro professores se delineia nessa sessão: o desenvolvimento das habilidades lingüísticas deve estar aliado a trabalho com temas, e estes devem problematizar questões vivenciadas no mundo social, como o respeito ao meio ambiente.

Nas reflexões sobre esse tópico, parece óbvia a influência dos PCN sobre Jonas e Márcia e a orientação de Ana Clara e Pedro Henrique mais voltada à abordagem comunicativa, o que é reflexo não só de sua experiência como alunos, mas também de sua formação e experiência profissionais. Em um continuum, tem-se Ana Clara, à esquerda, a favor da ênfase nas habilidades orais, e, à direita, Márcia, em defesa do foco na leitura. Pedro Henrique estaria mais próximo de Ana Clara, ao passo que Jonas estaria mais próximo de Márcia. Um ponto consensual entre eles é que o grande entrave ao desenvolvimento das quatro habilidades são os fatores contextuais e que o foco na leitura tem como vantagem a substituição da gramática pelo texto.

A nona sessão de reflexão, voltada para os resultados do processo de ensino e aprendizagem, foi o momento em que os quatro professores mais questionaram as próprias teorias práticas sobre o conteúdo e os objetivos, pois apenas um aluno de Ana Clara usou a língua de forma comunicativa e os alunos de Márcia, apesar de terem conseguido ler um texto sozinhos, demonstraram, na entrevista, ter desenvolvido pouco conhecimento sobre os temas trabalhados pela escola. A questão levantada por Ana Clara é: "Como é que a gente pode atingir a realidade desse aluno? Ou seja, trazer coisas para ele que façam sentido e que ele se sinta motivado a conhecer mais para transformar mesmo?”.

A orientação argumentativa subjacente à progressão dessas sessões reflexivas, ilustrada pelos trechos grifados acima, é a seguinte: 


\section{AFIRMAÇÃO DA PERSPECTIVA TRANSVERSAL \\ $\downarrow$ \\ AFIRMAÇÃO DA CENTRALIDADE DAS ATIVIDADES DE LEITURA \\ $\downarrow$ \\ NEGAÇÃO DA PERSPECTIVA TRANSVERSAL}

De fato, a autora (idem, ibidem: 10) percebe esse problema e comenta que a pergunta sobre como trabalhar os temas transversais fica sem resposta até o final do processo de entrevistas reflexivas, o qual se estendeu por mais de um ano, em suas várias etapas. Além disso, o que também chama a atenção nesse questionamento circular da reflexão dos professores, como um terceiro aspecto relevante, é o que não é dito. Os professores nunca se referem à interdisciplinaridade, e, portanto, às possibilidades de relacionamentos disciplinares do trabalho escolar, como algo relevante para o estabelecimento da transversalidade. Nesse sentido, os sujeitos entrevistados reproduzem a reação primeira ao aparecimento da proposta de transversalidade dos PCN, que foi uma tendência a pensá-la como um conjunto de temas alheios às disciplinas. No entanto, como veremos a seguir, esse entendimento está ligado também à concepção de atividades de leitura como modus operandi primordial da transversalidade.

Em princípio e por hipótese, é possível relacionar as dúvidas dos professores de Inglês ao apagamento de sua identidade disciplinar ${ }^{7}$ como resultado da compreensão equívoca da relação entre os eixos epistemológicos propostos pelos PCN para o trabalho escolar. Esse engano, que não foi inventado por eles e que deve ser esclarecido nas seções seguintes, leva os professores a acreditarem que práticas de linguagem não-centradas na leitura sejam "vazias" e a subvalorizarem as possibilidades interdisciplinares e transversais de atividades orais estabelecidas em práticas de ensino menos estruturadas. Por um lado, esse entendimento é fomentado pelo argumento de que 'como não é possível/produtivo ensinar a falar inglês, ensine-se a ler em inglês'. Por outro, a falta de explicitação sobre as complexas características epistemológicas da nova proposta para o trabalho escolar dificulta o gerenciamento de possíveis gradações de aplicação da nova matriz epistemológica.

7. Identidade disciplinar que foi construída em sua experiência de formação inicial com forte ênfase na competência comunicativa. 


\section{A OPERACIONALIZAÇÃo dos CONCEITOS DE INTERDISCIPLINARIDADE E DE TRANS- Versalidade em uma prática teórica da Lingüística Aplicada}

Enquanto, na seção anterior, a problematização da questão da transversalidade foi localizada em teorias práticas de professores, nesta parte do estudo o foco recai sobre a relação entre aquele conceito e o de interdisciplinaridade, tal como foram parcialmente apropriados dos PCN por uma obra de divulgação vinculada aos estudos do currículo e às pesquisas de LA de língua materna (Kleiman e Moraes, 1999) ${ }^{8}$.

A concepção da nova organização do trabalho escolar expressa pela referida obra é diretamente relacionada à dos PCN, apesar do seu diálogo com outras fontes teóricas. Em síntese, trata-se de uma proposta de operacionalização das mudanças curriculares que assume o princípio de que a transversalidade é "uma nova maneira de olhar os mesmos conteúdos, de certa forma imposta por problemas pelos quais a sociedade atravessa", e que preconiza o seu tratamento através de projetos colaborativos interdisciplinares no espaço intertextual das atividades de leitura (idem, ibidem: 10 e ss.). Suas autoras apresentam exemplos bastante detalhados de diferentes modalidades de projetos pedagógicos que têm como ponto de partida a leitura de notícias e reportagens de revistas semanais de informação e propõem sua inserção e derivação em estudos interdisciplinares. Com base em análises muito realistas das condições de possibilidade do trabalho escolar', essa abordagem lingüístico-pedagógica propõe-se a explorar a natureza interdisciplinar e transversal desse tipo de material jornalístico devido ao seu fácil acesso e à sua concomitância com os acontecimentos socialmente relevantes a que se relacionam (sua 'atualidade').

No entanto, apesar da inegável qualidade de suas sugestões de organização do trabalho escolar em torno das atividades de leitura ${ }^{10}$, essa proposta didática reproduz, em alguma medida, aquilo que parece ser uma imprecisão teórica criada pelos PCN na expressão dos novos eixos organizadores das prá-

8. Como esclarecem suas autoras (p. 11), o livro resultou de um curso de formação continuada para professores da rede pública e da pesquisa empírica em escolas do Estado de São Paulo. Sua relevância para o nosso estudo advém do fato de ser dirigido especialmente para os profissionais da educação, conformando um exemplo bastante pertinente do tipo de interlocução que os sujeitos da pesquisa referida na seção anterior têm em seus espaços de formação continuada e de avaliação profissional.

9. Sobretudo em relação à falta de recursos.

10. Escapa às possibilidades deste estudo reproduzir em detalhes a proposta de Kleiman e Moraes (1999), para o que remeto os leitores à consulta direta da obra. 
ticas de ensino. O primeiro aspecto do problema é uma falsa dicotomia entre o epistemológico e o pedagógico nas práticas escolares (Kleiman e Moraes, 1999: 22 - grifos nossos):

Segundo os Parâmetros Curriculares Nacionais (PCN), a interdisciplinaridade e a transversalidade se fundamentam na crítica de uma concepção que toma a realidade como um conjunto de dados estáveis, sujeitos a um ato de conhecer isento e distanciado. Diferem uma da outra no sentido que a interdisciplinaridade refere-se a uma abordagem epistemológica dos objetos de conhecimento questionando a segmentação entre os diferentes campos do saber produzida por uma visão compartimentada (disciplinar), que apenas informa sobre a realidade sobre a qual a escola, tal como é conhecida, historicamente se constituiu. Já a transversalidade refere-se a uma abordagem pedagógica que possibilite ao aluno uma visão ampla e consciente da realidade brasileira e sua inserção no mundo, bem como sua participação social.

Na concepção dos PCN, reproduzida pelo trecho acima, parece haver uma sobreposição parcial e contraditória das definições apresentadas. As instituições escolares são, por excelência, o locus do ensino formal e, por decorrência necessária e inescapável, qualquer abordagem escolar é, sempre, epistemológica e pedagógica. Em outras palavras, toda prática escolar contém um direcionamento de atividades de constituição e sistematização de objetos de conhecimento, ainda que não possa ser reduzida a esse aspecto apenas. Esse tipo de equívoco, mesmo que possa parecer irrelevante, está diretamente relacionado a dúvidas como aquelas apresentadas pelos professores na discussão da seção anterior e, em princípio, será considerado como resultante de um problema de transposição de perspectivas epistemológicas da pesquisa científica para o trabalho escolar ${ }^{11}$.

$\mathrm{Na}$ abordagem teórica em questão, entretanto, essa imprecisão não é estável. Por um lado, sua assimilação parece ser relativa à confusão entre "relacionamento disciplinar" e "ensino de valores", como se pode ver a seguir (idem, ibidem: 27; 43 - grifos nossos):

A instrução interdisciplinar aproveita-se das conexões naturais e lógicas que cruzam as áreas de conteúdos e organiza-se ao redor de perguntas, temas, problemas ou projetos, em lugar de conteúdos restritos aos limites das disciplinas tradicionais. [...] Não podemos minimizar a importância dos conteúdos e dar excessivo peso aos valores. O equilíbrio entre o disciplinar e o interdisciplinar é necessário, pois as áreas

11. Isso quer dizer que a transversalidade também é uma transposição desse tipo. Veja-se a seção seguinte. 
específicas possuem um cabedal de conhecimento acumulado ao qual o aluno deverá também ter acesso.

Sem negar completamente a relação proposta nos trechos acima, entendemos que, em um plano de coerência teórica para a proposta geral dos PCN, a interdisciplinaridade não se diferencia do ensino disciplinar pelo objetivo do "ensino de valores", o qual também não é interdito à organização disciplinar do trabalho escolar. Além disso, como a transversalidade também é conceituada como uma abordagem ao trabalho escolar que propicia a "inclusão de valores" (idem, ibidem: 23), esse aspecto deixaria de ser útil para uma definição desses eixos com finalidades operatórias.

Por outro lado, essa indiferenciação reduz-se, na proposta em questão, à medida que suas sugestões práticas vão sendo apresentadas. Ao discutirem a especificidade da formação de leitores, a noção de interdisciplinaridade é reafirmada como "a construção de uma rede de conhecimentos que remetem às diversas disciplinas", a qual seria constituída pelas conexões intertextuais das práticas de letramento escolares (idem, ibidem: 81). Em todas as suas sugestões de práticas, os aspectos relativos às atividades de leitura recebem, de fato, desdobramentos interdisciplinares. As autoras sugerem a consideração da transferência de concepções e conceitos de base entre as disciplinas com relação aos gêneros discursivos, às estratégias e às práticas de leitura, às formas de representação e linguagem etc. No entanto, no exame de outros tipos de relacionamento entre as disciplinas escolares, a descrição das suas contribuições recíprocas não chega a esse nível de abstração, restringindo-se a listas de conteúdos e práticas disciplinares organizadas em torno de um núcleo temático ou de uma questão social. Por exemplo, em um dos projetos comentados, as autoras assinalam as questões da hegemonia discursiva da língua inglesa na formação de siglas de uso internacional (como "AIDS") e da ordem da frase nominal desse idioma, em comparação com a do português, sem, no entanto, especificar sistematicamente o que seriam os aspectos disciplinares, interdisciplinares e transversais nesse caso (idem, ibidem: 84$)^{12}$.

Como veremos a seguir, esse último aspecto da proposta de Kleiman e Moraes pode conduzir a uma organização pluridisciplinar e não, propriamente, interdisciplinar para o trabalho escolar, de um modo geral. A explicitação operatória e sistemática relativa às práticas de leitura, que é a preocupação central da obra, não se faz também em uma perspectiva mais abrangente, em relação a outros objetivos do ensino. A falta desse mesmo 12. O que se deve, em parte também, pelos limites desse tipo de transposição do discurso científico para o profissionalizante, naturalmente. 
procedimento teórico na consideração de origens disciplinares diferentes, e não apenas de práticas de linguagem, leva os professores ao tipo de questionamento que se viu na primeira seção. A tradição pluridisciplinar da escola apropria-se desse tipo de proposta, tomando o seu ponto de vista como geral e suficiente. É preciso, portanto, esclarecer teoricamente o quadro geral de relacionamentos epistemológicos, de modo a poder operacionalizá-lo a partir de qualquer origem disciplinar.

\section{UMA REVISÃO DA ESPECIFIDADE OPERACIONAL DA NOVA MATRIZ EPISTEMOLÓGICA}

Em princípio, é possível considerar que, ao lado da metáfora de "rede", que é usada pela abordagem analisada acima na explicação das novas perspectivas do trabalho escolar, outras figuras também sejam úteis para a compreensão das possibilidades de relacionamento das práticas de ensino na escola, como as de "grade" e "matriz", por exemplo. À diferença da figura da imagem de uma rede de atividades, marcadamente pedagógica, as outras duas referemse aos limites epistemológicos que possibilitam a organização do trabalho escolar em redes e ao seu relacionamento estrutural. Em outras palavras, para se trabalhar com as derivações "abertas" da "rede" é preciso saber lidar ou vir a conhecer as origens "fechadas" das grades disciplinares no escopo das matrizes interdisciplinar e transversal. Nesse sentido, as grades disciplinares seriam redutíveis às referidas matrizes ou delas deriváveis; as matrizes, por sua vez, devem ser entendidas como "estruturas" ou grades que constituem grades disciplinares ${ }^{13}$.

De fato, a noção de interdisciplinaridade tem sido constituída em interface com outras similares que se referem a diferentes modos de relacionamentos disciplinares, como as de multidisciplinaridade, pluridisciplinaridade e transdisciplinaridade (Iribarry, 2003: 3) ${ }^{14}$. Considerando-se que uma disciplina seja "um conjunto sistemático e organizado de conhecimentos com características próprias em seus planos de ensino, de formação, de métodos e de matérias", a disciplinaridade seria "a exploração científica e especializada

13. Essa formulação, evidentemente, remonta à perspectiva estruturalista, no seu viés construtivista ou no chamado "estruturalismo epistemológico": não com vistas a um "fundo mais real que o Real", mas como uma geração de modelos mais abrangentes e explicativos (ver Eco, 2001).

14. A primeira parte da revisão epistemológica que procederei sobre o trabalho escolar apóia-se na resenha sobre as relações de disciplinaridade feita por Iribarry (2003), o qual a deriva de Japiassu (1976), Caon (1998) e Nicolescu (1999). A discussão sobre transversalidade, no entanto, é de minha conta e risco. 
de determinado domínio homogêneo de estudo"15. Relativamente ao âmbito científico da produção do conhecimento, uma caracterização dos planos de disciplinaridade, então, pode ser feita de acordo com o tipo de relacionamento estabelecido entre as diferentes disciplinas (idem, ibidem: 4 e ss.):

Multidisciplinaridade: um conjunto de disciplinas instanciadas em um mesmo nível, com objetivos diversos e sem cooperação.

Pluridisciplinaridade: o mesmo que multidisciplinaridade, mas com algum grau de relacionamento, ainda que sem coordenação hierárquica.

Interdisciplinaridade: disciplinas conectadas por axiomas comuns e com algum tipo de finalidade de hierarquia superior, envolvendo diferentes graus de aplicação metodológica.

Transdisciplinaridade: uma profunda conexão entre as disciplinas, promovendo uma descontinuidade estrutural e a superação axiomática das origens disciplinares, de acordo com propósitos empíricos específicos.

Dada essa classificação, é fácil reconhecer, por um lado, a associação da pluridisciplinaridade à escola tradicional e, por outro, a dificuldade de transferência da transdisciplinaridade para as práticas de ensino dos níveis fundamental e médio ${ }^{16}$. A abordagem multidisciplinar é possível em qualquer nível do ensino escolar, quando os diferentes objetivos dizem respeito aos diferentes objetos das matérias de ensino, aplicados isoladamente. Na pluridisciplinaridade, por sua vez, sempre no plano educativo, os objetos das disciplinas podem ser parcialmente conectados, geralmente por matérias da mesma área e no âmbito dos objetivos de cada disciplina: entre História e Geografia, Matemática e Ciências etc. Há ainda a possibilidade de uma coordenação geral, mas não hierárquica: todas as disciplinas ligam-se por temas e atividades comuns, sem, no entanto, haver um ponto de vista epistemológico organizador que relacione suas categorias e conceitos de base. Essa hierarquização, ou seja, esse quadro epistemológico mais geral e abstrato que reúne as diferentes disciplinas em um mesmo conjunto é o que se chamaria, corretamente, de

15. A esse respeito, vejam-se as "complexidades discursivas" do conceito de disciplina instauradas por Michel Foucault (2002).

16. Apesar disso, já há experiências escolares neste sentido tanto no Brasil como no exterior, de modos muito variáveis e fora do escopo deste artigo, que trata do caso específico dos paradigmas oficiais. 
abordagem interdisciplinar no âmbito das práticas escolares. Além disso, em regra, a passagem das relações científicas interdisciplinares para as práticas de ensino recebe o filtro de alguma perspectiva teórica da educação, como o "comportamentalismo", o "construtivismo" e o "socioconstrutivismo" etc.

Assim, uma abordagem interdisciplinar é, em qualquer caso, aquela que promove um tipo de movimento epistemológico mais "abstratizante" ainda e não apenas o emparelhamento dos métodos, conteúdos e pontos de vista disciplinares. Sob os conteúdos já abstratos das disciplinas, conceitos como 'enunciado', 'texto', 'estrutura', 'processo', 'sistema', 'relação', 'representação', 'leitura' etc. permeiam cada grade disciplinar e são comuns a todos os procedimentos de construção de conhecimento no trabalho escolar. Na abordagem interdisciplinar, essas conexões são operacionalmente mobilizadas, explicitadas e transferidas entre as disciplinas, de acordo com a(s) perspectiva(s) sobre ensino-aprendizagem adotada(s). A interdisciplinaridade forma, como foi dito, uma "grade das grades disciplinares" ou uma "matriz"17 dessas grades. Nesse sentido, as remissões de Kleiman e Moraes (op.cit.) sobre as práticas de leitura, as características dos gêneros discursivos e as linguagens específicas das várias disciplinas ensejam conhecimentos comuns a todas elas, que são propriamente interdisciplinares. Do mesmo modo, a questão da ordem da frase em inglês e em português, comentada na seção anterior, propiciaria a sistematização da noção de 'ordem', a qual é comum às outras disciplinas também, relativamente a outros conceitos como o de 'sistema' e 'processo' na área de Ciências, por exemplo. Como no caso das práticas de leitura, todas as transferências ou derivações abstratizantes devem ser explicitadas e sistematizadas na medida das possibilidades e das dimensões do trabalho escolar, com seus contextos, níveis e modalidades variáveis, para que se estabeleça a interdisciplinaridade.

Já a transversalidade, segundo a sua concepção nos PCN, envolve o trabalho com "temas transversais", grandes conjuntos de questões sociais importantes e urgentes, os quais não constituiriam outras disciplinas, mas, ao contrário, "atravessariam" os conteúdos das matérias já existentes. Nesse sentido, por exemplo, o ensino de valores não seria objeto de cursos escolares como os de "Moral e Cívica, "Religião" ou "Filosofia", como já ocorreu em passado recente e começa a acontecer novamente nas práticas escolares ${ }^{18}$. Questões como o "respeito ao próximo e a si mesmo", por exemplo, deveriam

17. O sentido do termo 'matriz', portanto, refere-se, neste estudo, a um tipo de 'grade' ou 'quadro' epistemológico mais profundo e abrangente.

18. Com a reintrodução de disciplinas como as de Sociologia e a de Filosofia no currículo escolar, há uma tendência de que elas centralizem e hegemonizem algumas questões propriamente transversais. 
ser tratadas em atividades de ensino ligadas a todas as disciplinas.

Vemos, portanto, que há dois aspectos importantes nessa perspectiva que não são bem especificados pela formulação oficial inicial ou por seus comentadores. Um deles é a origem igualmente disciplinar das questões sociais agrupadas e descritas em temas transversais pelos PCN. Essas questões foram constituídas dentro de ciências sociais como a Sociologia, a Antropologia, a Filosofia e, mesmo, a Medicina, entre outras. Desse modo, as questões sociais dos temas transversais ${ }^{19}$ têm também uma organização disciplinar como as questões da disciplina de História, que já aparece na grade curricular e que, por seu turno, é também uma outra origem dos temas transversais. Qual seria a razão, então, para que certas fontes disciplinares fossem "transversalizadas" e outras não? A resposta é "nenhuma"; isso não é coerente e deve ser explicado.

O segundo aspecto, por decorrência, é o fato de que a entrada coerente da transversalidade para o âmbito da proposta geral dos PCN não pode dizer respeito apenas a origens disciplinares que sempre trataram de questões e valores sociais. Se todas as disciplinas podem, em princípio ser associadas ao "ensino de valores" e se a interdisciplinaridade é um relacionamento mais abstratizante e abrangente dos recortes disciplinares, a transversalidade só pode ser entendida como um tratamento mais abrangente de outro aspecto também disciplinar: o do enfrentamento de questões "concretas". Pensada como uma abordagem "concretizante" para o trabalho escolar, e não "abstratizante", como a da interdisciplinaridade, a transversalidade também representaria um plano mais geral de organização do trabalho escolar, pertinente a todas as disciplinas tradicionais. Assim, quando os PCN propõem que questões sociais sejam apresentadas aos alunos ou constituídas pelos estudantes nas práticas escolares e que haja um enfrentamento dessas questões que implique e mobilize os alunos para a transformação social, o viés estabelecido pela abordagem transversal já não é o mesmo da ciência, nem mesmo o das ciências sociais: trata-se de um viés narrativo.

Entendemos que, a partir da leitura disciplinar das Ciências Sociais e Aplicadas, os temas transversais foram constituídos pelos PCN na seleção de problemas e questões em cuja materialidade devem ser instanciadas as experiências pessoais e coletivas dos sujeitos das práticas escolares: são questões pertinentes a narrativas experenciais, por sua 'atualidade' e por sua 'implicabilidade'. Sob o filtro dessas ciências sociais, a nova epistemologia do trabalho escolar apresenta tais questões como problemas "reais" para esses sujeitos, ou

19. Os temas transversais, nos PCN de 1998, eram: "Ética", "Pluralidade Cultural", "Meio Ambiente", "Saúde", "Orientação Sexual" e "Trabalho e Consumo". 
seja, recobertos de 'tempo', 'espaço', 'identidades' e 'pontos de vista' localizáveis nas práticas sociais de cada um deles e de suas comunidades. Assim, nessa concepção, a transversalidade seria o "avesso" da interdisciplinaridade ou sua complementação dialética; ambas são constitutivas do tratamento operacional das disciplinas tradicionais (daí serem suas 'matrizes').

Como a escola e o trabalho escolar são ainda dirigidos por professores cuja formação é, sobretudo, disciplinar, as matrizes da interdisciplinaridade e da transversalidade devem ser (re)constituídas a partir dessas origens profissionais e, ao mesmo tempo, ser (re)constitutivas delas no trabalho escolar. Por outro lado, no caso dos alunos, que não têm a mesma experiência de formação dos professores, a perspectiva transversal apresenta-se com maior relevância no início do processo de escolarização, tendendo para o equilíbrio com a perspectiva da interdisciplinaridade na medida do sucesso das práticas de ensino e de seus modelos disciplinares, ao final da Educação Básica (o que conforma, efetivamente, a entrada do sujeito escolarizado para o mundo da ciência e da tecnologia, no âmbito do Ensino Superior).

A escola, apesar de participar da produção social do conhecimento, não é o espaço de produção científica, por excelência. As disciplinas, em primeiro lugar, e a interdisciplinaridade, sobretudo, são portais entre o ensino e a ciência e suas técnicas e tecnologias. Do mesmo modo, a escola não é o espaço da vida cotidiana das práticas sociais, mas uma redução institucional dessas práticas sociais ao âmbito da educação. A transversalidade é a ponte entre as práticas sociais e o ensino. E, dessa forma, ambas, interdisciplinaridade e transversalidade, são matrizes para os conteúdos disciplinares e para as questões sociais, operados por meio das grades das matérias escolares (conforme a representação gráfica apresentada - ver Figura 1 a seguir).

Como se vê, uma aplicação operacional coerente das proposições epistemológicas que se originam nos PCN, em sua formulação inicial, dependeria de um também complexo relacionamento das práticas discursivas escolares. $\mathrm{O}$ gerenciamento do trabalho em "rede", essa nova forma de organizar processos de produção, distribuição e consumo de textos, decorreria do entendimento de suas relações intertextuais em uma perspectiva interdiscursiva. 


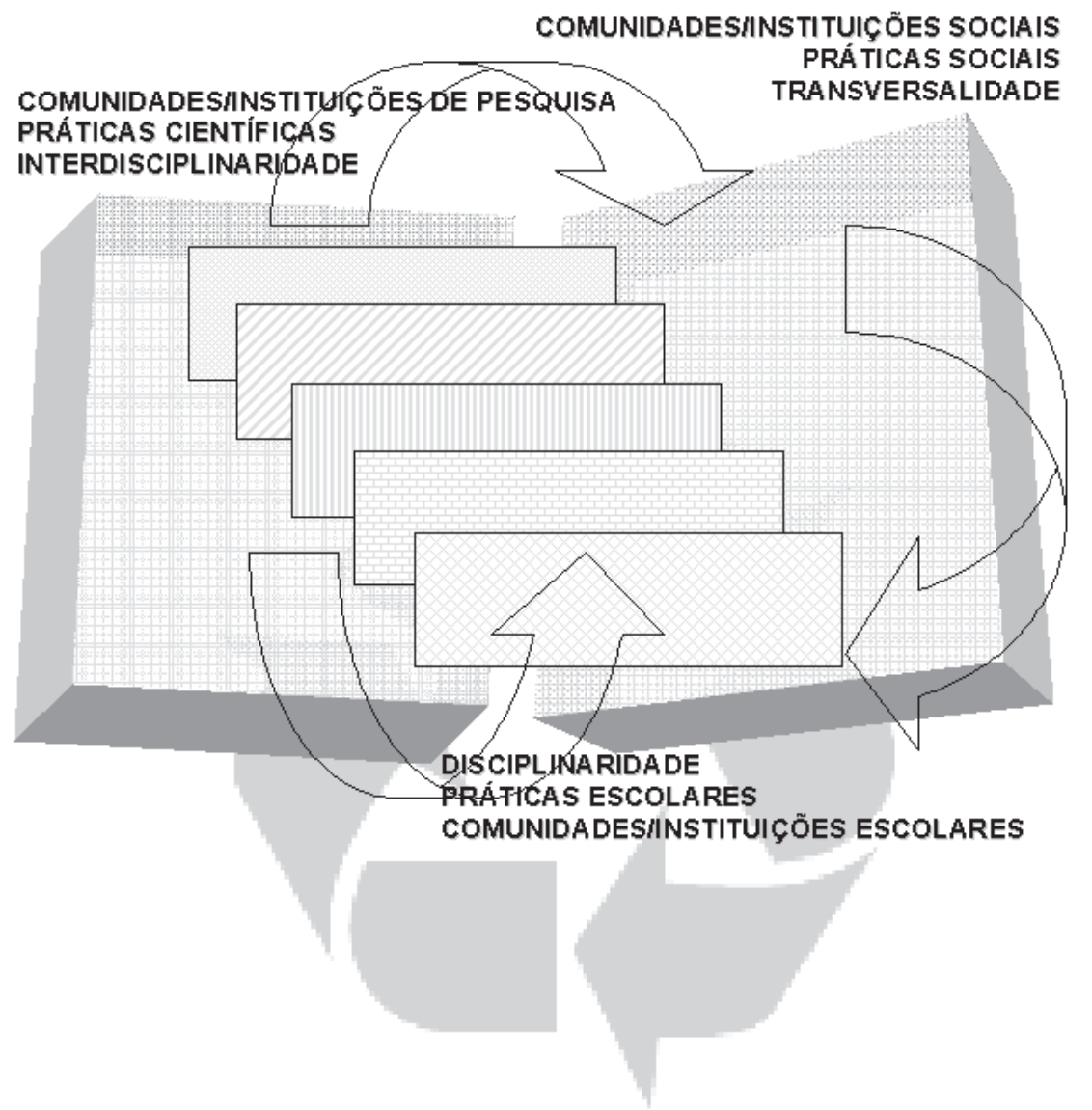

Figura 1 - Relações epistemológicas do trabalho escolar (Costa, 2007: 178).

Não se trata, como se lê no PCN e em derivações profissionalizantes, de um eixo 'epistemológico' e outro 'pedagógico'. Tanto a interdisciplinaridade quanto a transversalidade têm origens epistemológicas e conseqüências pedagógicas. Nessa nova ordem de discurso escolar (Fairclough e Chouliaraki, 1999; Costa, 2005), os modos de produção, distribuição e consumos de textos, as práticas discursivas, dizem respeito não apenas à intensa valorização do trabalho coletivo de professores e alunos, como meio de produção dos relacionamentos disciplinares demandados, mas também à compreensão operativa das racionalidades discursivas das duas matrizes: o viés narrativo da transversalidade e o viés abstrato da interdisciplinaridade. 
Nesse sentido, a aplicação coerente da proposta geral dos PCN, desde a sua proposição inicial, passava pela consideração do nível de "estruturação" dos contextos escolares, ou seja, das condições de possibilidade da aplicação dessas grades e matrizes ao trabalho escolar. Por exemplo, voltando ao questionamento dos professores de Inglês sobre o trabalho com temas transversais no ensino de língua estrangeira, discutido na primeira seção só poderia basearse em relacionamentos epistemológicos ligados a identidade disciplinar dessa área. Em outras palavras, aqueles professores tinham uma formação disciplinar específica que os vinculava a objetivos pedagógicos particulares que os mantinha vinculados a um núcleo de conteúdos e competências mais ou menos estabilizados. Por maior que fosse a sua participação em relacionamentos interdisciplinares e transversais, esses profissionais haviam ingressado no sistema de ensino em função de uma contribuição específica e necessária para o trabalho escolar e de acordo seus limites. E o mesmo vale para todas as áreas e sujeitos da escola. Além das inclinações disciplinares dos diferentes 'tipos' de professores, alunos de comunidades específicas também vão identificar-se com percursos transversais particulares, o que trará demandas e consequiências disciplinares e interdisciplinares diversas para o trabalho escolar.

Na primeira reformulação da epistemologia do trabalho escolar (a de 1998), portanto, já havia muitos sentidos e direções possíveis para o estabelecimento de "redes" ou percursos intertextuais para as práticas pedagógicas, os quais eram sempre relativos aos níveis de estruturação comunitária, institucional e profissional dos espaços escolares locais. Vejamos os percursos mais previsíveis:

- Origem disciplinar isolada: a partir de sua própria abordagem disciplinar isolada, o professor produz mobilizações interdisciplinares e transversais em suas aulas.

- Origem pluridisciplinar: professores de áreas próximas trabalham conjuntamente conceitos e temas relativos às suas disciplinas.

- Origem transversal: a partir de um tema transversal ou de uma de suas questões, professores de áreas próximas ou de todas as áreas fazem as derivações transversais, disciplinares e interdisciplinares. Neste caso, os projetos pedagógicos tornam-se um instrumento extremamente produtivo, mas não são imprescindíveis.

- Origem interdisciplinar: a partir de conceitos interdisciplinares, com ou sem projetos pedagógicos, os professores de áreas próximas ou de todas as áreas derivam atividades transversais e disciplinares. 
Em qualquer dos percursos exemplificados acima, os professores precisam apropriar-se dos conteúdos e conceitos-chave das outras áreas disciplinares para poderem operar com as abordagens transversal e interdisciplinar. No caso da disciplina de Inglês, por exemplo, o desenvolvimento integral das habilidades comunicativas é constitutivo tanto da competência profissional de seus professores, e por isso de sua identidade, como da justificativa da sua presença no quadro epistemológico do currículo escolar. $\mathrm{O}$ discurso sobre o 'privilégio da leitura nas aulas de língua estrangeira' não é apenas redutor de sua operacionalização interdisciplinar, mas também um absurdo transversal: na experiência narrativa (vivencial) dos alunos, não é apenas assim que se lhes apresenta o 'objeto' da disciplina ${ }^{20}$. Desconsiderar esses aspectos, em princípio, dificultava a esses professores apropriarem-se das outras perspectivas e estabilizarem a sua participação nessa nova ordem epistemológica e discursiva do trabalho escolar. Em outras palavras, é possível sim trabalhar com temas transversais por meio de atividades comunicativas sem o estabelecimento da centralidade das práticas de leitura. Entretanto, o funcionamento dessa nova e complexa disposição epistemológica deve ser apropriado pelo professor, para que ele possa conhecer as possibilidades e os limites de sua atuação, gerenciando e atualizando a sua inserção no trabalho escolar de acordo com o seu contexto específico.

\section{Conclusão}

Finalmente, é preciso salientar que em documentos posteriores - como os $P C N+$ e as Orientações Curriculares - os aspectos aqui discutidos são integrados à discussão sobre a interdisciplinaridade com o apagamento parcial da noção de transversalidade no discurso pedagógico oficial. Em linhas gerais, essas reformulações dos paradigmas epistemológicos salientaram aquilo que aqui chamamos de relacionamento ainda mais abrastratizante da interdisciplinaridade, privando o viés narrativo de enfrentamento do aluno a questões e problemas concretos de um tratamento operacional explícito. Portanto, apesar de isso ser previsível, já que a interdisciplinaridade sempre foi mais compreensível e menos arriscada do que a transversalidade ${ }^{21}$, a solução do defeito de sobreposição

20. Tal concepção só pode ter origem em experiências de 'leitura instrumental', de origem marcadamente acadêmica. Na vida cotidiana, alunos de todas as classes sociais têm uma experiência e uma concepção fortemente oral da língua estrangeira (sobretudo no caso da língua inglesa!).

21. Parte da proposta original da transversalidade era relativa ao enfrentamento ime- 
que apontamos inicialmente parece ter seguido pelo caminho mais "fácil”, em lugar de radicalizar o ganho que o tratamento dos temas transversais representava para o tão propalado objetivo de uma "educação cidadã".

\section{ReferênCIAS Bibliográficas}

Brasil. Orientações curriculares para o ensino médio. Linguagens, códigos e suas tecnologias. Brasília: Ministério da Educação, Secretaria de Educação Básica, 2006.

Brasil. Ministério da Educação e do Desporto. Secretaria de Educação Fundamental. Parâmetros Curriculares Nacionais: terceiro e quarto ciclos do ensino fundamental: língua estrangeira. Brasília, 1998.

Brasil. Ministério da Educação e do Desporto. Secretaria de Educação Fundamental. Parâmetros Curriculares Nacionais: terceiro e quarto ciclos do ensino fundamental: temas transversais. Brasília, 1998.

Chouliaraki, N.; Fairclough, L. Discourse in late modernity. Edimburgo: Universty Press, 1999.

Costa, A. Arqueologia da formação do professor. A nova ordem de discurso da educação nacional. Campinas (SP), 2007. Tese (Doutorado) - Programa de Pós-Graduação em Lingüística Aplicada, Universidade Estadual de Campinas.

Costa, A. A formação de professores na nova ordem de discurso da educação brasileira. Cadernos de Linguagem e Sociedade, 7, Brasília, 34-45, 2004/2005. ISSN 0104-9712.

Eco, U. A estrutura ausente. 7 ed. São Paulo: Perspectiva, 2001.

Foucault, M. A arqueologia do saber. 6 ed. Rio de Janeiro: Forense Universitária, 2002.

Iribarry, I. N. Aproximações sobre a transdisciplinaridade. Algumas linhas históricas, fundamentos e princípios aplicados ao trabalho de equipe. Psicologia: Reflexão e Crítica, 16 (3), 2003. ISSN 0102-7972.

diato de problemas e questões sociais. Se, por um lado, essa abordagem era fortemente integradora do aluno nas práticas pedagógicas, por outro, sempre se apresentou como uma "falha" na cerca que separa a escola da "vida real", algo nada fácil de ser gerenciado em contextos tão desestruturados como os das escolas brasileiras. 
Kleiman, A. B. (Org.) Os significados do letramento. Uma nova perspectiva sobre a prática social da escrita. Campinas, SP: Mercado de Letras, 1995.

Kleiman, A. B.; e Moraes, S. E. Leitura e interdisciplinaridade. Tecendo redes nos projetos da escola. Campinas, SP: Mercado de Letras, 1999.

Pessoa, R. R. Reflexão interativa. Desvelando e transformando teorias práticas sobre o ensino de inglês na escola pública. Mimeo, 2005.

Pessoa, R. R. A reflexão interativa como instrumento de desenvolvimento profissional. Um estudo com professores de inglês da escola pública. Belo Horizonte, 2002. Tese (Doutorado) - Programa de Pós-Graduação em Letras/ Estudos Lingüísticos, Universidade Federal de Minas Gerais.

Doutor em Lingüística Aplicada pela Universidade Estadual de Campinas; Professor Adjunto da Faculdade de Letras da Universidade Federal de Goiás. alexanrs@uol.com.br 